\title{
Tropical Indian Ocean Influence on Northwest Pacific Tropical Cyclones in Summer following Strong EI Niño*
}

\author{
YAN DU AND LEI YANG \\ LED, South China Sea Institute of Oceanology, CAS, Guangzhou, China \\ SHANG-PING XIE \\ IPRC, and Department of Meteorology, University of Hawaii at Manoa, Honolulu, Hawaii, and POL, \\ Ocean University of China, Qingdao, China
}

(Manuscript received 14 June 2010, in final form 29 September 2010)

\begin{abstract}
In the summer following a strong El Niño, tropical cyclone (TC) number decreases over the Northwest (NW) Pacific despite little change in local sea surface temperature. The authors' analysis suggests El Niñoinduced tropical Indian Ocean (TIO) warming as the cause. The TIO warming forces a warm tropospheric Kelvin wave that propagates into the western Pacific. Inducing surface divergence off the equator, the tropospheric Kelvin wave suppresses convection and induces an anomalous anticyclone over the NW Pacific, both anomalies unfavorable for TCs. The westerly vertical shear associated with the warm Kelvin wave reduces the magnitude of vertical shear in the South China Sea and strengthens it in the NW Pacific, an eastwest variation that causes TC activity to increase and decrease in respective regions. These results help improve seasonal TC prediction.
\end{abstract}

\section{Introduction}

El Niño-Southern Oscillation (ENSO) affects tropical cyclone (TC) activity in the northwest (NW) Pacific, including number, genesis, and intensity. Atkinson (1977) first found that more TCs form eastward in the NW Pacific during the developing phase of El Niño. A southeastward displacement of TC genesis was identified (Chen et al. 1998; Chan 2000; Wang and Chan 2002). As a result, the TCs' lifetime and intensity both increase. The relationship between TC number and ENSO is not very robust, but TC number tends to increase in strong El Niño events (Chan 2000; Wang and Chan 2002). Wang and Chan (2002) attributed this TC enhancement to the shear vorticity of low-level westerly wind anomalies near the equator during El Niño. Other studies relate it to the

\footnotetext{
* International Pacific Research Center/School of Ocean and Earth Science and Technology Publication Number 730/8037.

Corresponding author address: Yan Du, South China Sea Institute of Oceanology, 164 West Xingang Road, Guangzhou 510301, China.

E-mail: duyan@scsio.ac.cn
}

increase in accumulated cyclone energy or potential intensity (Camargo and Sobel 2005; Wing et al. 2007; Camargo et al. 2007). Wang and Chan (2002) noted that ENSO influences on TCs may linger until July(1), but the mechanism was unclear. [Numbers in parentheses denote phases of ENSO: (0) and (1) indicate developing and decay years, respectively.] An independent study by Zhan et al. (2011) investigate the contributions of ENSO and east Indian Ocean (EIO) SST to the TC in the NW Pacific and find the EIO effect is mostly on weak TCs.

El Niño teleconnection induces a robust basinwide warming over the tropical Indian Ocean (TIO; Klein et al. 1999), which persists through summer when El Niño itself has dissipated in the equatorial Pacific (Izumo et al. 2008; Du et al. 2009). Much like a discharging capacitor, the TIO warming anchors robust atmospheric anomalies during June-August [JJA(1); Yang et al. 2007], including suppressed convection and an anomalous surface anticyclone over the subtropical NW Pacific (Wang et al. 2003). This TIO teleconnection is accomplished by a warm Kelvin wave that propagates into the western Pacific and induces off-equatorial surface wind divergence (Xie et al. 2009). As the surface anticyclone and reduced convection are both unfavorable for TCs, the TIO warming 

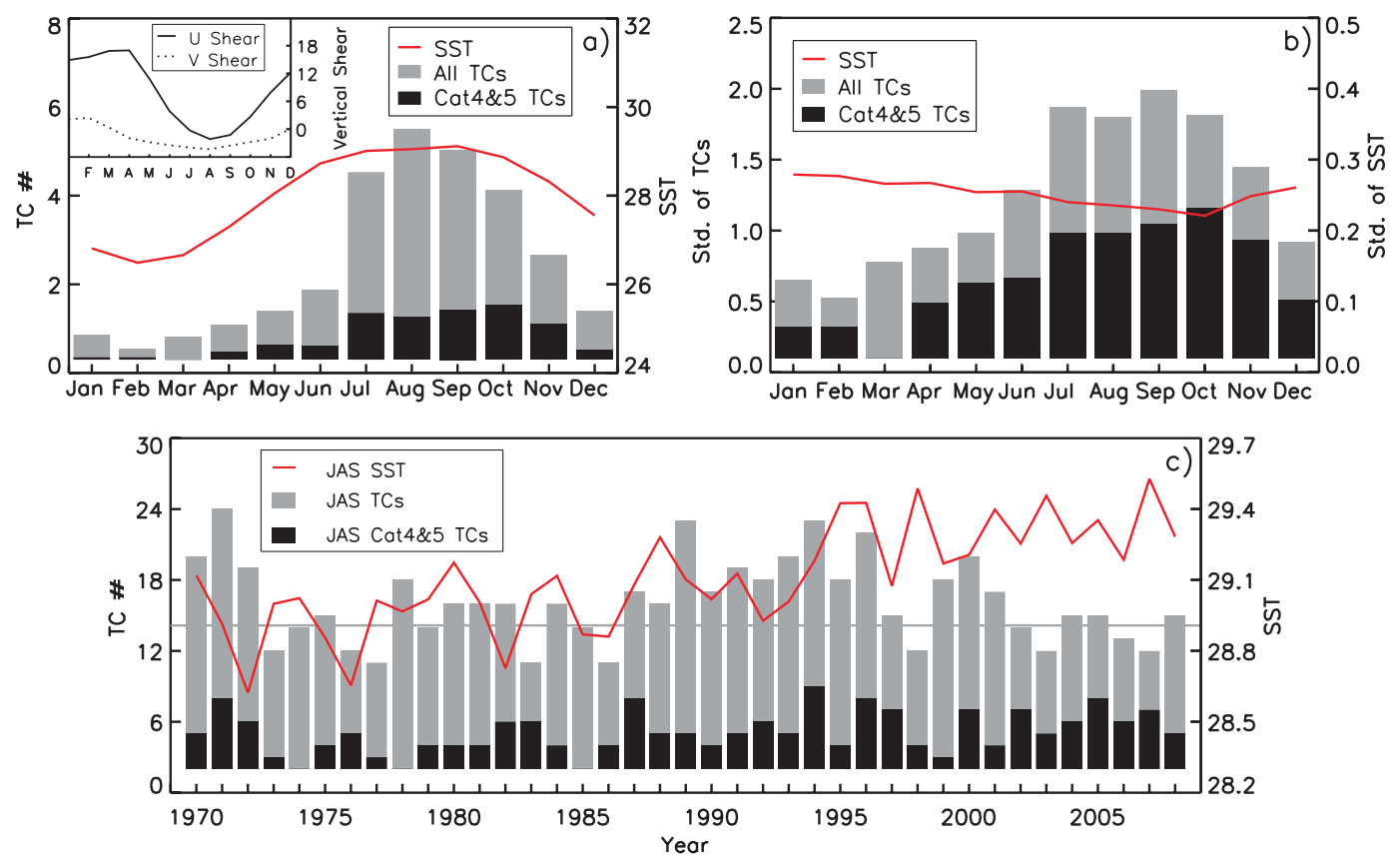

FIG. 1. Number of TCs and category 4 and 5 TCs in the NW Pacific during 1970-2008: (a) seasonal variation, (b) standard deviation by month, and (c) interannual variation in JAS (climatological mean shown in the gray line). SST (red line) averaged in the same region $\left(5^{\circ}-25^{\circ} \mathrm{N}, 120^{\circ}-180^{\circ} \mathrm{E}\right)$ is superimposed. Wind vertical shear is included in the left corner of (a).

conceivably affects TC activity during the early TC season in the El Niño decay year.

The present study investigates this possibility. We show that there are indeed robust TC anomalies during the TC season [July-September (JAS)] following the El Niño decay [JAS(1)]. Our analysis relates them to environmental parameters such as low-level vorticity and vertical shear.

\section{Data and methodology}

We use the best-track dataset including TC location and intensity at 6-h intervals produced by the Joint Typhoon Warning Center (JTWC). It covers the TIO, South China Sea (SCS), and NW Pacific. Our study focuses on the SCS and NW Pacific. A TC is defined as a storm with closed cyclonic circulation and sustained winds of $25 \mathrm{kt}$ or above. For satellite observations, data in and after the 1970s are considered of high quality. Our analysis covers a 39-yr period (1970-2008). JTWC data compare favorably with Emanuel's (2005) dataset after the 1970s (Wing et al. 2007).

Environmental variables are derived from the U.S. National Centers for Environmental Predication (NCEP) reanalysis (Kalnay et al. 1996) and sea surface temperature (SST) data from the NCEP extended SST analysis (Smith et al. 2007). In our composite analysis, a 4-84-month bandpass filter is applied to extract interannual anomalies. Reanalysis precipitation compares favorably in the NW Pacific to that of the Global Precipitation Climatology Project (GPCP) for 1979-2008 (Adler et al. 2003); a period for which observations from the latter are available.

Genesis potential (GP) is calculated following Emanuel and Nolan (2004): GP $=\left|10^{5} \eta\right|^{3 / 2}(H / 50)^{3}\left(V_{\text {pot }} / 70\right)(1+$ $\left.0.1 V_{\text {shear }}\right)^{-2}$, where $\eta$ is the absolute vorticity at 850 $\mathrm{hPa}\left(\mathrm{s}^{-1}\right), H$ is the relative humidity at $700 \mathrm{hPa}(\%)$, $V_{\text {pot }}$ is the potential intensity (PI; Bister and Emanuel $2002)$, and $V_{\text {shear }}$ is the wind vertical shear (200 $\mathrm{hPa}-$ $850 \mathrm{hPa} ; \mathrm{m} \mathrm{s}^{-1}$ ). PI calculation is based on the NCEP daily product and averaged to monthly mean for GP calculation and further analysis. We compare the GP result with the previous studies and find that the spatial distribution and season variations are consistent with Camargo et al. (2007, their Fig. 1) and Yokoi et al. (2009, their Figs. 4i and 6f) (figures not shown).

\section{NW Pacific TC variability}

TC number in the NW Pacific shows a pronounced annual cycle, peaking in August. $25 \%$ of TCs are classified as category 4 or 5 , about one per month during the major TC season of July-October (Fig. 1a). During the TC season, SST is high and wind vertical shear (200 minus $850 \mathrm{hPa}$ ) is small, illustrating the importance of these environmental conditions. Interannual variability in TC number is high during the TC season, about two per 
month in standard deviation. Local SST variability does not display clear seasonality.

Figure 1c shows JAS SST and TC numbers over the NW Pacific for the past four decades. Their correlation is low as noted in the literature (Chan and Liu 2004; Chan 2007). We note a decrease in TC number in JAS(1) following El Niño. JAS TCs are fewer than 12 in 7 out of 39 years, all following El Niño except 1986. (The climatological count is 14.2.) The rest of the paper examines composites based on three major El Niño events of $1972 / 73,1982 / 83$, and $1997 / 98$ to study how remote SST anomalies modulate TC activity for JAS.

Figure 2 shows the composite evolution of key indices. Niño-3.4 SST peaks at $2.5^{\circ} \mathrm{C}$ in year(0), inducing a robust basinwide warming in TIO that peaks in year(1) at $\sim 0.5^{\circ} \mathrm{C}$. The TIO warming persists through the following TC season JAS(1), intensifying local atmospheric convection and inducing atmospheric anomalies in the NW Pacific (Xie et al. 2009). In JAS(1) over $5^{\circ}-25^{\circ} \mathrm{N}, 120^{\circ}-$ $180^{\circ} \mathrm{E}$, there are fewer TCs than normal with unfavorable environmental conditions: vertical shear is stronger, surface wind vorticity anomaly is negative, rainfall is less, and sea level pressure (SLP) is higher. TC number and environmental parameters show a biennial tendency, with opposing anomalies between JAS( 0 ) and JAS(1). Local SST anomalies do not seem important for NW Pacific TCs, positive during JAS(1) when rainfall and TC anomalies are both negative. The monthly genesis potential follows closely the TC count, suggesting that the change of environmental factors causes variations in TC activity. TC anomalies have been studied extensively in the literature for JAS(0) but not for JAS(1).

Figure 3 compares TC tracks and anomalies of TC occurrence between JAS(0) and JAS(1), superimposed on SST anomalies. Over the NW Pacific (not including SCS), the total number of TCs for these three major El Niño events decreases by $33 \%$ (44 to 29 ) from JAS(0) to JAS(1), despite a general increase in local SST. The decrease in long-lived TCs (those lasting for seven days or longer) is much greater: a $60 \%$ decrease, from 33 to 13 . In the SCS, by contrast, TCs and long-lived TCs both increase in number from JAS(0) to JAS(1).

a. $\operatorname{JAS}(0)$

In JAS(0), SST is anomalously warm in the central/ eastern equatorial Pacific, characteristic of a developing El Niño. TC genesis shows a distinct southeast shift (Fig. 3a) as noted by previous studies (e.g., Wang and Chan 2002; Cheung 2004). Forming farther away from the Asian coast in the southeast corner of the NW Pacific around $5^{\circ}-15^{\circ} \mathrm{N}, 150^{\circ}-180^{\circ} \mathrm{E}$, TCs are not so easily dissipated over warm waters (Camargo and Sobel 2005). This helps increase the TC lifetime.
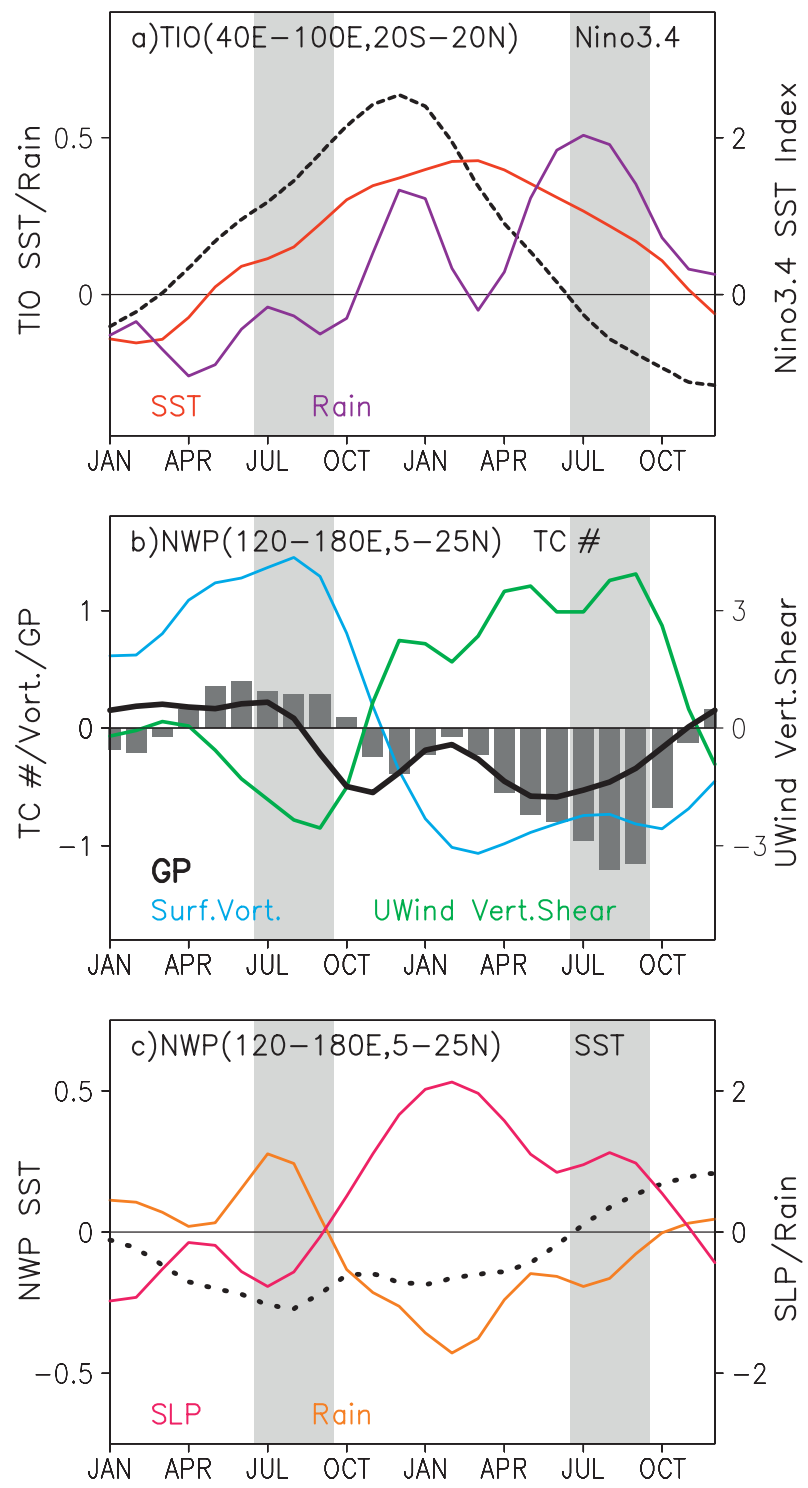

FIG. 2. Evolution of key indices composited on three strong El Niño events (1972/73, 1982/83, and 1997/98): (a) SST $\left({ }^{\circ} \mathrm{C}\right)$ and rain rate $\left(\mathrm{mm} \mathrm{day}^{-1}\right)$ in TIO, superimposed on the Niño-3.4 SST index; (b) TC number (gray bars), genesis potential (GP), zonal wind vertical shear $\left(200 \mathrm{hPa}-850 \mathrm{hPa} ; \mathrm{m} \mathrm{s}^{-1}\right)$, and surface wind vorticity $\left(10^{-6} \mathrm{~s}^{-1}\right)$ in the NW Pacific (NWP); and (c) NWP sea level pressure (SLP; $\mathrm{hPa}$ ) and rain rate, superimposed with local SST. Long light gray bars highlight JAS(0) and JAS(1).

The left panels of Fig. 4 show JAS(0) anomalies of environmental parameters important for TCs. Enhanced convection over the subtropical NW Pacific helps shape TC activity during JAS $(0)$ by inducing low-level cyclonic vorticity and moistening the midtroposphere. Tropospheric temperature averaged over $200-850 \mathrm{hPa}$ increases in the tropics in response to the developing El Niño. The offequatorial maxima in tropospheric warming are due to 

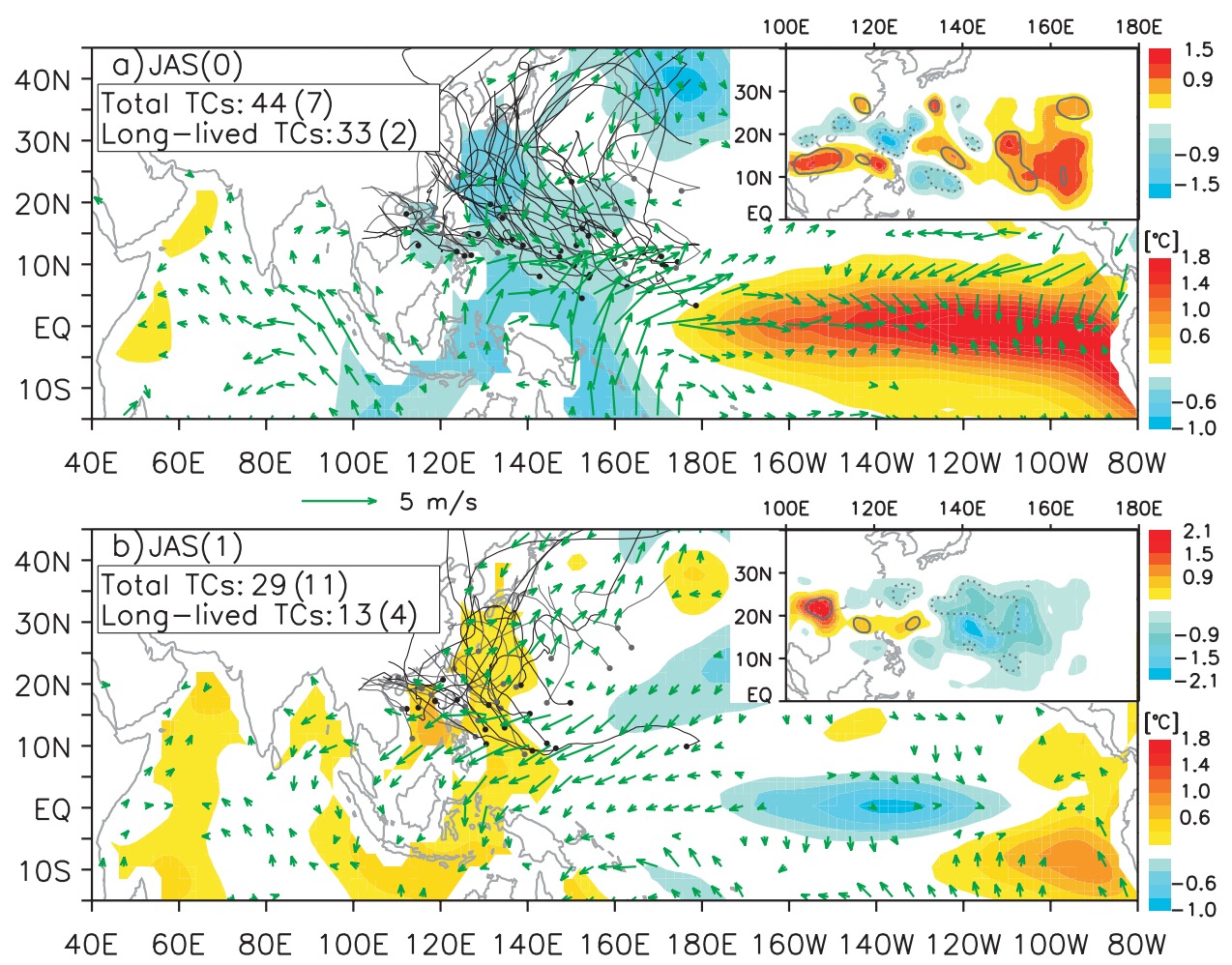

FIG. 3. The TC tracks and anomalies of surface wind and SST (shading, ${ }^{\circ} \mathrm{C}$ ) in the NW Pacific for three strong El Niño events in (a) JAS(0) and (b) JAS(1). Black lines are for long-lived TCs and gray for other TCs. Total TC numbers are shown on the upper-left corner for the NW Pacific $\left(5^{\circ}-25^{\circ} \mathrm{N}, 120^{\circ}-180^{\circ} \mathrm{E}\right)$ and for SCS in parentheses. The TC occurrence anomaly (per JAS season) is shown in the inset in the upper right corner; the $95 \%$ confidence level is shown in gray contours.

westward-propagating Rossby waves. The warm Rossby wave extends farther westward north than south of the equator because of enhanced convection in the NW Pacific. Off the equator, vertical wind shear is in thermal balance with tropospheric temperature. In the central North Pacific, the easterly shear anomalies on the south flank of the warm Rossby wave reduce the mean westerly shear (Figs. 4b,c), creating a favorable condition for the anomalous southwest shift in TC genesis during JAS $(0)$ (Fig. 3a). GP anomalies are generally consistent with TC occurrence anomalies in Fig. 3, increasing (decreasing) east (west) of $140^{\circ} \mathrm{E}$ at $10^{\circ}-20^{\circ} \mathrm{N}$. This confirms the role of the above environmental parameters.

\section{b. $J A S(1)$}

During JAS(1), TC activity weakens over the NW Pacific, with the number decreasing from 44 in JAS(0) to 29. The TC number decrease is particularly large in the southeast corner of the NW Pacific $\left(5^{\circ}-15^{\circ} \mathrm{N}, 150^{\circ}-\right.$ $180^{\circ} \mathrm{E}$ ), from 16 to 1 , most of them long-lived storms. TC number increases in the SCS, however, reaching 11 in JAS(1) compared to the climatology of 6 for three JAS seasons.
In JAS(1) over the NW Pacific, convection weakens, accompanied by negative surface vorticity and drying the midtroposphere. All these conditions are unfavorable for TCs (Fig. 4e). The TIO remains warm while the equatorial Pacific displays a weak cooling, a sign of developing La Niña (Fig. 3b). Both the TIO warming and equatorial Pacific cooling probably contribute to the suppressed convection and anomalous anticyclone in the NW Pacific, via Kelvin wave-induced Ekman divergence (Xie et al. 2009) and Rossby waves, respectively. Compared to JAS(0), SST anomalies are weak and limited in zonal extent over the equatorial Pacific whereas they are robust over the TIO.

Vertical shear appears important for TC anomalies in JAS(1). The TIO warming excites a warm Kelvin wave propagating into the western Pacific with a maximum in tropospheric warming on the equator (Fig. 4f; Lau et al. 2005; Xie et al. 2009). The vertical shear anomalies are westerly, associated with this warm baroclinic Kelvin wave. Since the mean vertical shear is easterly west and westerly east of $150^{\circ} \mathrm{E}$ in the subtropical NW Pacific $\left(10^{\circ}-20^{\circ} \mathrm{N}\right)$, the magnitude of vertical shear decreases west and increases east of $150^{\circ} \mathrm{E}$ (Fig. $4 \mathrm{~g}$ ). The reduced 

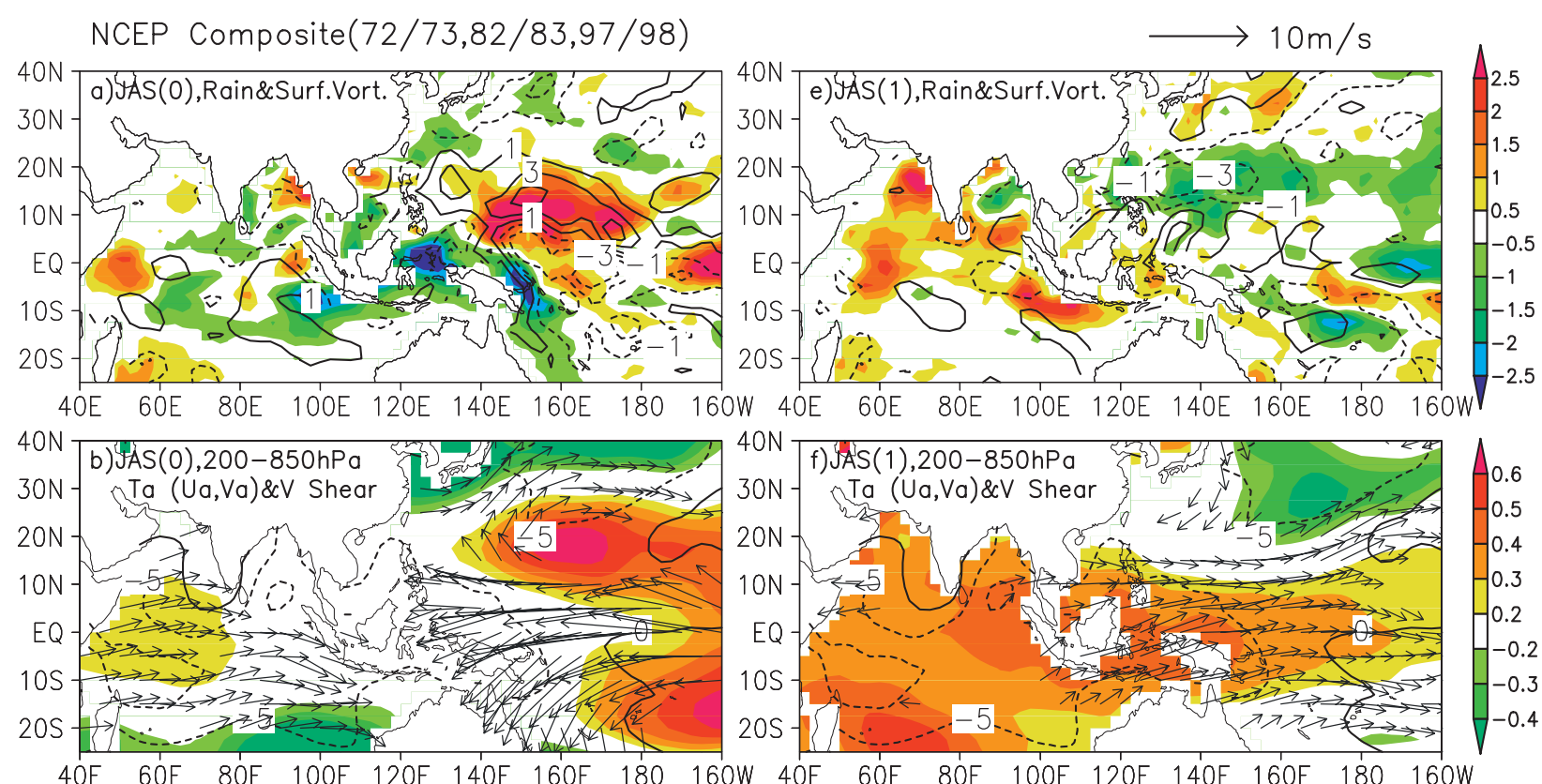

40E 60E 80E 100E 120E 140E 160E 180 160W 40E 60E 80E 100E 120E 140E 160E 180 160W
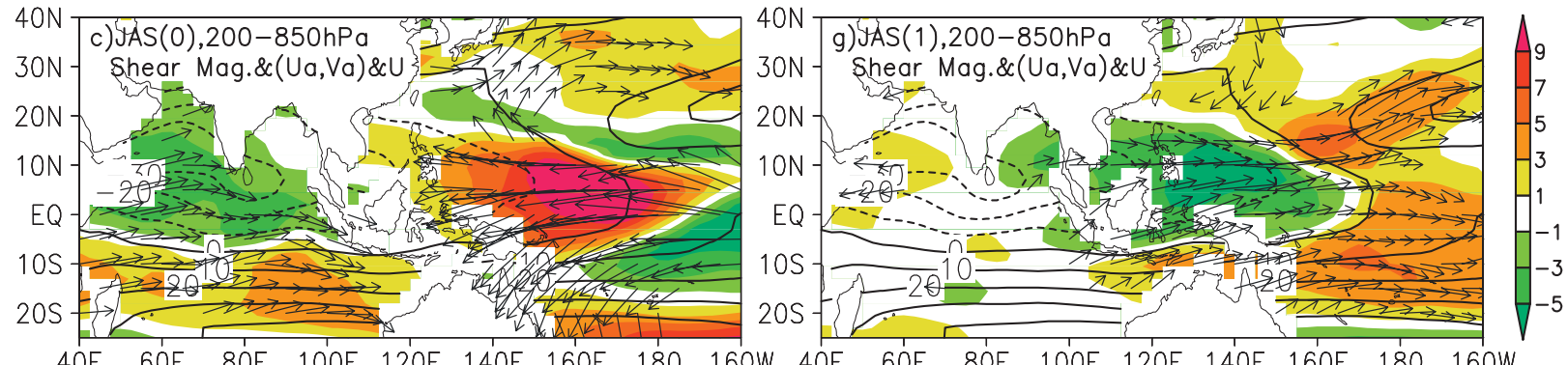

40E 60E 80E 100E 120E 140E 160E 180 160W 40E 60E 80E 100E 120E 140E 160E 180 160W
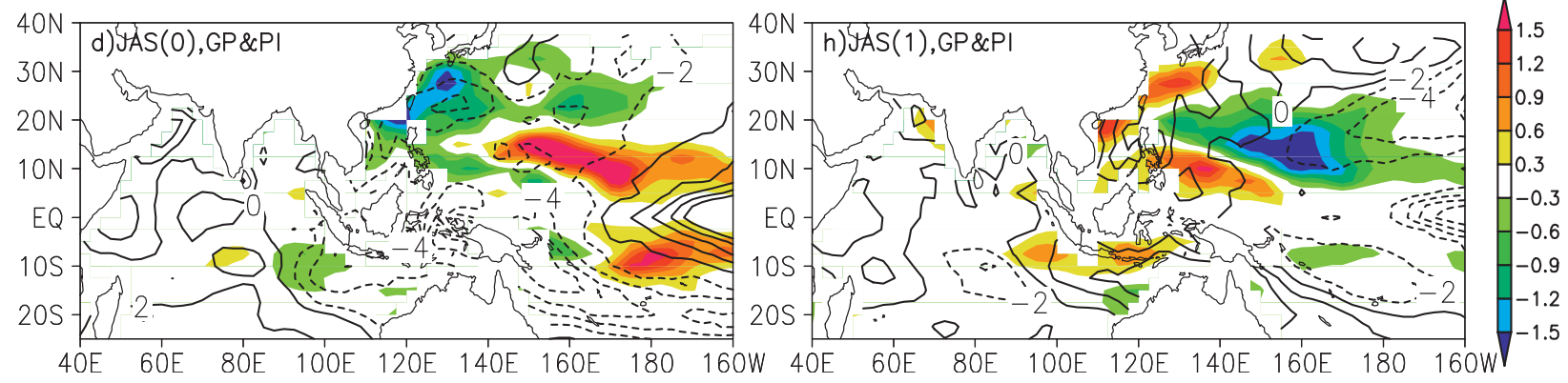

FIG. 4. Strong El Niño composites for (left) JAS(0) and (right) JAS(1). (a),(e) Anomalies of rain rate (shading, mm day $^{-1}$ ) and surface wind vorticity (contour, $\left.10^{-6} \mathrm{~s}^{-1}\right)$; (b),(f) anomalies of tropospheric $\left(200-850 \mathrm{hPa}\right.$ ) temperature (shading, $\left.{ }^{\circ} \mathrm{C}\right)$ and $(200-850 \mathrm{hPa})$ vertical shear vectors, along with mean meridional wind vertical shear (contour, $\mathrm{m} \mathrm{s}^{-1}$ ); (c), (g) vertical shear magnitude anomaly (shading, $\mathrm{m} \mathrm{s}^{-1}$ ) and mean zonal wind vertical shear (contour, $\mathrm{m} \mathrm{s}^{-1}$ ), with the same vectors as in (b); (d),(h) anomalies of monthly genesis potential (GP) (shading) and potential intensity (PI) (contour; $\mathrm{m} \mathrm{s}^{-1}$ ).

vertical shear intensifies TC activity over the SCS while the increased vertical shear suppresses it in the southeast corner of the NW Pacific. SST anomalies, strongly positive in the SCS and weakly negative in the NW Pacific, may also contribute to this east-west contrast in JAS(1) TC response. This zonal contrast is present in GP anomalies (Fig. 4h), largely consistent with patterns of wind shear and PI anomalies.

\section{Discussion}

\section{a. Indian Ocean effect}

A linear baroclinic model (LBM) is used to illustrate the importance of the Indian Ocean warming on wind shear over the SCS and NW Pacific during JAS(1). The detailed description of the LBM is referred to Watanabe and Kimoto (2000). Following the specifications of 

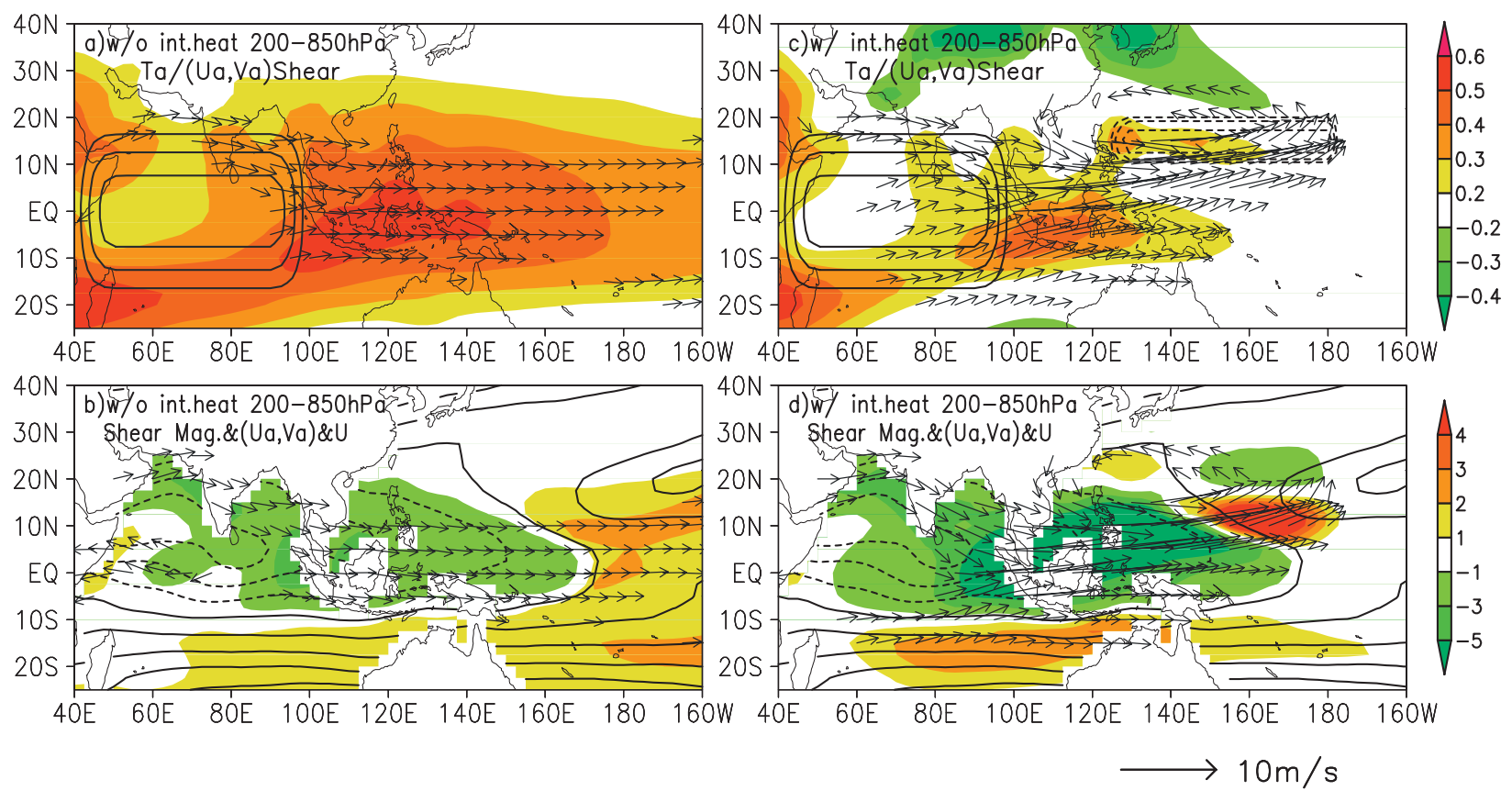

FIG. 5. The linear atmospheric model response to TIO heating (left) without and (right) with interactive convective heating over the NW Pacific: (a),(c) anomalies of tropospheric (200-850 hPa) temperature (shading, $\left.{ }^{\circ} \mathrm{C}\right)$ and $(200-850 \mathrm{hPa})$ vertical shear vectors; (b), (d) anomalies of vertical shear vectors and magnitude (shading, $\mathrm{m} \mathrm{s}^{-1}$ ) and mean zonal wind vertical shear (contour, $\mathrm{m} \mathrm{s}^{-1}$ ).

Xie et al. (2009), we use a mean state of the JAS climatology and a vertical profile of perturbation diabatic heating that is confined between 900 and $100 \mathrm{hPa}$ and peaks at $500 \mathrm{hPa}$. We impose broad heating over the TIO $\left(20^{\circ} \mathrm{S}-\right.$ $\left.20^{\circ} \mathrm{N}, 40^{\circ}-100^{\circ} \mathrm{E}\right)$ to represent the SST warming during JAS(1). The model reaches a quasi-steady state after 15 days. A warm Kelvin wave response is clearly visible in the tropospheric temperature in the western Pacific (Fig. 5a). The TIO warming causes significant anomalies of vertical wind shear. The perturbation westerly shear of the warm Kelvin wave reduces the vertical shear in the SCS and increases it east of $150^{\circ} \mathrm{E}$ (Fig. 5b), consistent with observations in Fig. 4f.

As in Xie et al. (2009), we perform another run by introducing an interactive heating in the NW Pacific $\left(10^{\circ}-20^{\circ} \mathrm{N}, 120^{\circ}-180^{\circ} \mathrm{E}\right)$, based on observations in Fig. $4 \mathrm{~d}$. The convective heating there is parameterized as a linear function of surface convergence. In response to the same TIO heating, the vertical wind shear is significantly strengthened with the interactive diabatic cooling in the NW Pacific (Figs. 5c,d). Vertical shear anomalies from the LBM bear striking similarities to observations (Fig. 4f) over the NW Pacific. The reduced shear over the SCS and enhanced shear to the east centered at $15^{\circ} \mathrm{N}$, $160^{\circ} \mathrm{E}$ are due both to the warm Kelvin wave and to the NW Pacific convective cooling. The general agreement between the LBM experiment and observations supports that the Kelvin wave forced by the TIO warming is a major cause of wind shear change in the SCS and NW Pacific during JAS(1), which in turn affects TCs as manifested in an east-west dipole of TC activity between the regions (Fig. 3b).

\section{b. Comparison with a developing La Niña}

La Niña often follows a strong El Niño. Figure $3 b$ shows a weak SST cooling in central equatorial Pacific. JAS(1) tropospheric temperature anomalies in Fig. 4e show a strong equatorial Kelvin wave compared to the Rossby wave to the north, the former due to the TIO warming (Xie et al. 2009) and the latter to both negative SST anomalies over the equatorial Pacific and suppressed convection over the NW Pacific. To identify the effect of La Niña, all La Niña events in JAS(0) without a preceding El Niño are composited together to illustrate the wind shear response. La Niña events from 1970/71, 1971/ $72,1974 / 75,1975 / 76,1984 / 85,1999 / 2000$, and 2000/01 are selected. Figure 6a shows anomalies of tropospheric temperature and wind shear for La Niña JAS(0), which resembles El Niño JAS(0) except for a sign reversal, especially in the Rossby wave response over the NW Pacific. Compared to JAS(1), the warm Kelvin wave from the TIO is missing. Shear anomalies are much larger in El Niño JAS(1) than La Niña JAS(0). In the latter, vertical shear anomalies diminish over the SCS and are limited to the east of $130^{\circ} \mathrm{E}$ and in a narrow equatorial band of $10^{\circ} \mathrm{S}-10^{\circ} \mathrm{N}$. For El Niño JAS(1), by contrast, the 
NCEP Composite(70/71,71/72,74/75, $75 / 76,84 / 85,99 / 00,00 / 01)$
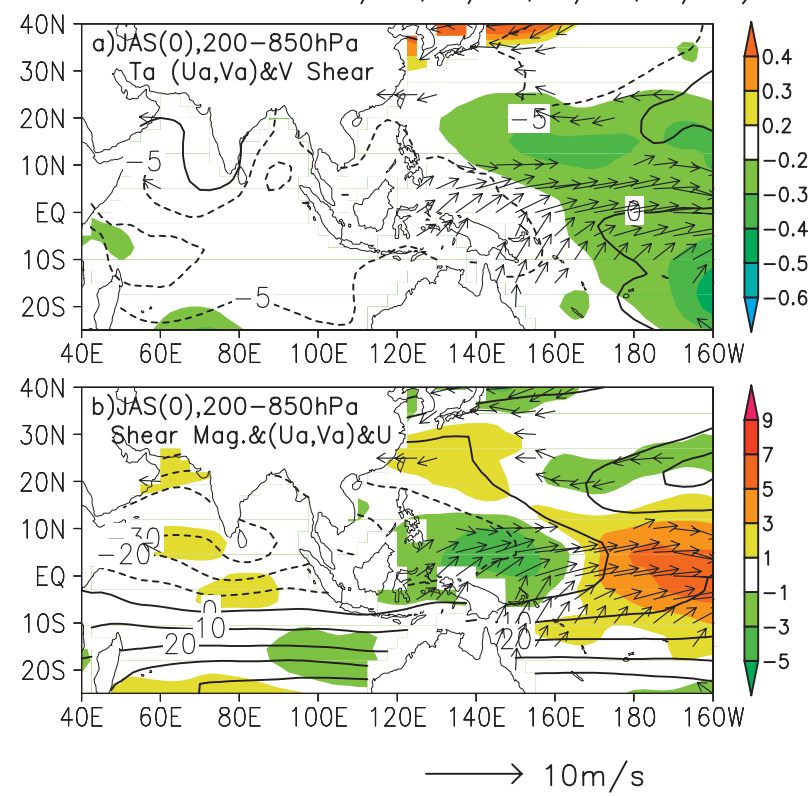

FIG. 6. As in Figs. 4e and 4f, but for La Niña JAS(0) composites.

shear increase in the central Pacific is located in the TC genesis region $\left(10^{\circ}-20^{\circ} \mathrm{N}\right.$; Fig. 4f). The most important difference between El Niño JAS(1) and La Niña JAS(0) is perhaps in the NW Pacific TC count, respectively 10 and 16 per year. The latter number is indistinguishable from El Niño JAS(0) at 15 per year. Detailed modeling studies are necessary for a quantitative evaluation of relative importance between the TIO warming and equatorial Pacific cooling.

\section{c. Year 2010}

So far, our discussion has focused on the JAS season. Figure $2 \mathrm{~b}$ shows a decrease in TC activity in the AprilJune(1) [AMJ(1)] season (Wang and Chan 2002). In the AMJ season of 1973, there was only one TC; and none occurred in 1983 or 1998. Year 2010 is very similar. No TC formed in the 2010 AMJ season. For the JAS season, 11 TCs formed over the NW Pacific, fewer than the climatological mean of 14.2. There were only four TCs from 1 July to 26 August (compared with the climatology of 8.3). On 27 August, Linrock became a TC, marking the beginning of a busy late TC season. On 30 August, there were three tropical storms over the NW Pacific: Linrock in the South China Sea, Namtheun near Taiwan, and Kompasu further to the east (http://weather.unisys.com/ hurricane/w_pacific/2010/index.html). A moderate El Niño took place with SST anomalies $>1{ }^{\circ} \mathrm{C}$ in the central equatorial Pacific from October 2009 to May 2010 (http:// nomad2.ncep.noaa.gov/ncep_data/index.html). During October 2009 to September 2010, the Indian Ocean $\left(20^{\circ} \mathrm{S}-20^{\circ} \mathrm{N}, 40^{\circ}-100^{\circ} \mathrm{E}\right)$ experienced a $0.4^{\circ}-0.6^{\circ} \mathrm{C}$ warming. The anomalous low TC activity in 2010 is typical of El Niño decay phase. In particular, the low TC count in the early TC season appears tied to an anomalously warm Indian Ocean.

\section{d. Effect of long-term SST warming}

Figure 1c shows that local SST is not a key factor regulating TC activity over the NW Pacific. The TC count even shows a decreasing trend after the mid-1990s despite a robust warming over the Indo-western Pacific Ocean since the 1950s (Du and Xie 2008). The ongoing and future warming differ from that associated with El Niño, the former being nearly spatially uniform and the latter confined in space. Vecchi and Soden (2007) proposed a relative SST warming concept: it is the spatial patterns of SST warming, not the warming itself, that determines convective instability of the atmosphere and hence PI (Xie et al. 2010). This is because fast equatorial waves flatten the tropospheric warming and makes it spatially uniform within the tropics. This result is consistent with the modeling study of Sugi and Yoshimura (2004). In the global warming case, relative SST warming is important through PI, while on interannual time scales, vertical shear appears dominant for TC variability (section 3 ).

\section{Summary}

This study reveals significant anomalies of NW Pacific TC activity during the TC season following El Niño. Our analysis reveals a sharp decrease in TC number during JAS(1), especially in the southeast corner of the NW Pacific $\left(5^{\circ}-15^{\circ} \mathrm{N}, 150^{\circ}-180^{\circ} \mathrm{E}\right)$. Local SST anomalies appear unimportant. Instead, the prolonged SST warming over the TIO is key to JAS(1) TC anomalies. By means of the Kelvin wave-induced Ekman divergence, it causes suppressed convection and maintains an anomalous anticyclone over the NW Pacific, both anomalies unfavorable for TCs. The warm tropospheric Kelvin wave emanating from the TIO is accompanied by westerly wind shear. It causes vertical shear to decrease in magnitude over the SCS and increase over the NW Pacific, an east-west variation that leads to increased and decreased TC activity in respective regions. This opposing response between the SCS and NW Pacific is due to the climatology where the mean wind shear is easterly and westerly in respective regions. While La Niña often follows El Niño, we show that patterns of tropospheric temperature and vertical shear anomalies are distinct between JAS(1) following large El Niño and La Niña JAS(0). They are also different in that the TC count decreases in El Niño JAS(1) but does not deviate significantly from climatology in La Niña JAS(0). 
Our results indicate that during JAS(1), landfall TCs increase on the northwest coast of the SCS but decrease in Taiwan and on the coast of Chinese provinces Fujian and Zhejiang (Fig. 3b, upper left inset). Such information can be used to improve long-lead TC forecasts, with the knowledge of the El Niño state three seasons in advance (Luo et al. 2008; Chowdary et al. 2010).

Acknowledgments. We wish to thank Dr. Dongxiao Wang of LED/SCSIO, Dr. Chunzai Wang of NOAA/ AOML for useful discussion, Jan Hafner of IPRC/UH for conducting LBM simulations, and Matt Kucas of JTWC for discussion on the 2010 TC season. The codes for PI calculation are obtained from Kerry A. Emanuel (via http://wind.mit.edu/ emanuel/home.html). This work is supported by the 973 Program (2010CB950302), NSFC (40876007), CAS (KZCX2-YW-BR-04), Qianren and Changjiang Scholar projects, U.S. NSF, and JAMSTEC.

\section{REFERENCES}

Adler, R. F., and Coauthors, 2003: The version 2 Global Precipitation Climatology Project (GPCP) monthly precipitation analysis (1979-present). J. Hydrometeor., 4, 1147-1167.

Atkinson, G., 1977: Proposed system for near real time monitoring of global tropical circulation and weather patterns. Preprints, 11th Tech. Conf. on Hurricanes and Tropical Meteorology, Miami Beach, FL, Amer. Meteor. Soc., 645-652.

Bister, M., and K. A. Emanuel, 2002: Low frequency variability of tropical cyclone potential intensity. 1. Interannual to interdecadal variability. J. Geophys. Res., 107, 4801, doi:10.1029/ 2001JD000776.

Camargo, S. J., and A. H. Sobel, 2005: Western North Pacific tropical cyclone intensity and ENSO. J. Climate, 18, 2996-3006.

$\longrightarrow$, K. A. Emanuel, and A. H. Sobel, 2007: Use of a genesis potential index to diagnose ENSO effects on tropical cyclone genesis. J. Climate, 20, 4819-4834.

Chan, J. C. L., 2000: Tropical cyclone activity over the western North Pacific associated with El Niño and La Niña events. J. Climate, 13, 2960-2972.

- 2007: Interannual variations of intense typhoon activity. Tellus, 59A, 455-460.

_- and K. S. Liu, 2004: Global warming and western North Pacific typhoon activity from an observational perspective. J. Climate, 17, 4590-4602.

Chen, T.-C., S.-P. Weng, N. Yamazaki, and S. Kiehne, 1998: Interannual variation in the tropical cyclone formation over the western North Pacific. Mon. Wea. Rev., 126, 1080-1090.

Cheung, K. K. W., 2004: Large-scale environmental parameters associated with tropical cyclone formations in the western North Pacific. J. Climate, 17, 466-484.

Chowdary, J. S., S.-P. Xie, J.-Y. Lee, Y. Kosaka, and B. Wang, 2010: Predictability of summer northwest Pacific climate in 11 coupled model hindcasts: Local and remote forcing. J. Geophys. Res., 115, D22121, doi:10.1029/2010JD014595.

Du, Y., and S.-P. Xie, 2008: Role of atmospheric adjustments in the tropical Indian Ocean warming during the 20th century in climate models. Geophys. Res. Lett., 35, L08712, doi:10.1029/ 2008GL033631.
,,-- G. Huang, and K. Hu, 2009: Role of air-sea interaction in the long persistence of El Niño-induced North Indian Ocean warming. J. Climate, 22, 2023-2038.

Emanuel, K. A., 2005: Increasing destructiveness of tropical cyclones over the past 30 years. Nature, 436, 686-688.

— climate. Proc. 26th Conf. on Hurricanes and Tropical Meteorology, Amer. Meteor. Soc., Miami, FL, 240-241.

Izumo, T., C. de Boyer Montegut, J.-J. Luo, S. K. Behera, S. Masson, and T. Yamagata, 2008: The role of the western Arabian Sea upwelling in Indian monsoon rainfall variability. J. Climate, 21, $5603-5623$.

Kalnay, and Coauthors, 1996: The NCEP/NCAR 40-Year Reanalysis Project. Bull. Amer. Meteor. Soc., 77, 437-471.

Klein, S. A., B. J. Soden, and N.-C. Lau, 1999: Remote sea surface temperature variations during ENSO: Evidence for a tropical atmospheric bridge. J. Climate, 12, 917-932.

Lau, N.-C., A. Leetmaa, M. J. Nath, and H. L. Wang, 2005: Influences of ENSO-induced Indo-western Pacific SST anomalies on extratropical atmospheric variability during the boreal summer. J. Climate, 18, 2922-2942.

Luo, J.-J., S. Masson, S. K. Behera, and T. Yamagata, 2008: Extended ENSO predictions using a fully coupled ocean-atmosphere model. J. Climate, 21, 84-93.

Smith, T. M., R. W. Reynolds, T. C. Peterson, and J. Lawrimore, 2007: Improvements to NOAA's historical merged land-ocean surface temperature analysis (1880-2006). J. Climate, 21, 2283 2296.

Sugi, M., and J. Yoshimura, 2004: A mechanism of tropical precipitation change due to $\mathrm{CO}_{2}$ increase. J. Climate, 17, 238-243.

Vecchi, G. A., and B. J. Soden, 2007: Effect of remote sea surface temperature change on tropical cyclone potential intensity. Nature, 450, 1066-1070.

Wang, B., and J. C. L. Chan, 2002: How strong ENSO events affect tropical storm activity over the western North Pacific. J. Climate, 15, 1643-1658

_, R. Wu, and T. Li, 2003: Atmosphere-warm ocean interaction and its impact on Asian-Australian monsoon variability. J. Climate, 16, 1195-1211.

Watanabe, M., and M. Kimoto, 2000: Atmosphere-ocean thermal coupling in the North Atlantic: A positive feedback. Quart. J. Roy. Meteor. Soc., 126, 3343-3369.

Wing, A. A., A. H. Sobel, and S. J. Camargo, 2007: Relationship between the potential and actual intensities of tropical cyclones on interannual time scales. Geophys. Res. Lett., 34, L08810, doi:10.1029/2006GL028581.

Xie, S.-P., K. Hu, J. Hafner, H. Tokinaga, Y. Du, G. Huang, and T. Sampe, 2009: Indian Ocean capacitor effect on Indo-western Pacific climate during the summer following El Niño. J. Climate, 22, 730-747.

, C. Deser, G. A. Vecchi, J. Ma, H. Teng, and A. T. Wittenberg, 2010: Global warming pattern formation: Sea surface temperature and rainfall. J. Climate, 23, 966-986.

Yang, J., Q. Liu, S.-P. Xie, Z. Liu, and L. Wu, 2007: Impact of the Indian Ocean SST basin mode on the Asian summer monsoon. Geophys. Res. Lett., 34, L02708, doi:10.1029/2006GL028571.

Yokoi, S., Y. N. Takayabu, and J. C. L. Chan, 2009: Tropical cyclone genesis frequency over the western North Pacific simulated in medium-resolution coupled general circulation models. Climate Dyn., 33, 665-683, doi:10.1007/s00382-009-0593-9.

Zhan, R., Y. Wang, and X. Lei, 2011: Contributions of ENSO and east Indian Ocean SSTA to the interannual variability of tropical cyclone frequency. J. Climate, in press. 